Article

\title{
A Routine Thermal Response Test (TRT) for Estimating Soil Thermal Properties in Connection with Geotechnical Analysis
}

\author{
Alessandro Franco \\ Department of Energy and System Engineering (DESTEC), University of Pisa, Largo Lucio Lazzarino - 56126 \\ Pisa, Italy; alessandro.franco@ing.unipi.it
}

\begin{abstract}
The performance of ground heat exchangers systems depends on the knowledge of the thermal parameters of the ground like thermal conductivity, thermal capacity and diffusivity. The knowledge of these parameters often requires quite accurate experimental analysis, known under the name of Thermal Response Test (TRT). In this paper, after a general analysis of the various available types of TRT and the study of the theoretical basics of the method, the perspective of the definition of a simplified routine method of analysis based on the combination of a particular version of TRT and the routine geotechnical tests for the characterization of soil stratigraphy and of the ground characteristics, mandatory before the construction of a new buildings, even if limited to quite short drilling depth (lower than $30 \mathrm{~m}$ ). The idea of developing TRT in connection with geotechnical test activity has the objective of promoting a widespread use of in-situ experimental analysis and of reducing TRT costs and time duration of the experimental analysis. The considerations exposed in the present paper lead to reconsider a particular variety of the TRT in particular the version known as Thermal Response Test while Drilling (TRTWD).
\end{abstract}

Keywords: Ground coupled Heat Exchangers; Thermal Response Test; Thermal conductivity; Thermal diffusivity; Geotechnical properties; Borehole heat exchangers

\section{Introduction}

Geothermal systems that use ground-coupled heat exchangers (GHE) and Ground Source Heat Pumps (GSHP) are becoming increasingly popular all over the world as a measure for energy saving for heating purposes. This is mainly true in the case of cold climate but the use of GSHP is extended to temperate climate situations too.

One of the elements of uncertainty in the design and sizing of geothermal heat pump systems is the definition of heat transfer with the ground and of the ground thermal properties.

Different types of heat exchangers, vertically or horizontally installed can be used. The most common vertical type is the Borehole Heat Exchanger (BHE). It consists of vertical boreholes heat exchangers (BHE) that are up to $100 \mathrm{~m}$ deep (but depth over than $100 \mathrm{~m}$ are available) and with a diameter of about $100 \mathrm{~mm}$. The number of boreholes connected to the heat pump installed in the bore field can range from one for a residential building to several dozens in case of commercial buildings or high size buildings. In horizontal applications, the heat exchanger consists of pipe-coils which are buried at an approximate depth of 1.5-3 m.

The performance of Ground Heat Exchangers mostly depends on the ground thermal parameters (conductivity and capacity) and the borehole resistance; a correct definition of those parameters requires preliminary experimental analysis.

Soil material can be considered a multiphase material composed of solid particles, water, and air. Each of the components in the soil has different thermal properties. The effective thermal properties of soils are highly dependent on the relative proportion of each component. As it is possible to understand from the literature, typical values of thermal properties of soil materials stand 
in the range between $0.25-8 \mathrm{~W} / \mathrm{mK}$ concerning the thermal conductivity $\lambda, 1.5-3 \mathrm{~kg} / \mathrm{m}^{3}$ for density $\rho$, and values between 0.7 and $2.0 \mathrm{~kJ} / \mathrm{kg} \mathrm{K}$ for the specific heat $\mathrm{cp}$. The diffusivity stands in the range between $10-6 \mathrm{~m}^{2} / \mathrm{s}$ and $4010-6 \mathrm{~m}^{2} / \mathrm{s}$. [1]

Thermal response test (TRT) is a routine method used to determine thermal properties of the ground necessary for the design of Ground Coupled Heat Pump (GCHP) systems. The conventional method with heat extraction or with both heat extraction and injection, evaluates the effective ground thermal conductivity, the borehole resistance and the undisturbed ground temperature; these parameters are vital crucial the design of a borehole heat exchanger (BHE), so maximum precision is required. A diffused literature about TRT is available and recently, different reviews have been published containing the different methods and apparatus developed and analyzed for in-situ tests. A comprehensive analysis of the method can be found in [2,3].

The test method is based on injection of heat obtained by means of water circulation into the ground and in the measurements of temperature variations. In particular water temperature variations are measured at the ground heat exchanger inlet and outlet during the test, along with flow rate. Measured temperature and flow rates are then analyzed with analytical or numerical models for interpretation. The conventional thermal response test is not particularly expensive but the achievable results are often poor (Poppei et al., [4]). Moreover, test duration is long (over 50 hours). The quite high cost of a TRT remains an issue that prevents its widespread use.

The aforesaid considerations permit to clearly understand the fact that research is particularly active in this field in the last years. More precisely, the efforts of the researchers aim to:

- improve the resolution of the thermal properties (of the ground) obtained; in this perspective, different version of the classical TRT have been developed, like DTRT (Acuña et al., [5]; Fujii et al., [6]), eTRT (Poppei et al., [4]) and TRTWD (Tuomas and Gustafsson, [7]);

- $\quad$ reduce and optimize the test duration: the version of TRT called TRTWD analyzed by [7] and the method called CHTM (Wang et al., [8]) can be related to this research area;

- $\quad$ simplify the test rig and the test procedures; this is what has been tried with the version referred as HC TRT (Raymond et al., [9]) and the TRT with natural stimulation (Poppei et al., [4]). - $\quad$ analyze the results of the TRT and carried out comparison of methods for the analysis of the experimental results (Zarrella et al., [10]), and in a reduced time scale (Pasquier et al., [11]).

Therefore, improvements do not concern only experimental analysis but mathematical models too. The common interpretation of the data is based on the use of analytical methods and numerical models: numerical models result in a more detailed description of the heat transfer process, accounting for 3-D phenomena (Signorelli et al., [12]), analytical models evolve losing simplifying assumptions, describing in a more actual way the complex interaction with the surface (Zeng et al., [13]; Lamarche and Beauchampe, [14]; Bandos et al., [15]; Marcotte and Pasquier, [16]).

An accurate analysis of the various experimental methods and models for the analysis of the experimental data developed for the TRT suggests that there are still wide improvement margins in the TRT development and that further improvements could be obtained combining the various proposals in literature. Moreover, as consequence of the market expansion, the need for standardisation and quality insurance has been recognized so that the development of new and fast methods can be highly appreciated. The problem is that TRT is not widespread because it is considered expensive and the experimental analysis requires a quite long time (from three to five days). For this reason, the sizing of the ground heat exchangers is therefore based on the application of some empirical data: the range considered is from 20 to $100 \mathrm{~W}$ for each meter of borehole heat exchanger. But this often determine an oversizing of the ground source heat exchanger with a not optimal operation of the heat pump during time.

The acquisition of some preliminary experimental data, like those available for TRT could be really useful. An idea for increasing the application of TRT for design purposes could be the connection of the procedure with standard geo-technical investigations, mandatory according to the 
Law of a lot of countries. In particular, reducing drilling depth below $30 \mathrm{~m}$ could permit the use of geotechnical drilling materials and techniques that are less expensive.

A geotechnical investigation includes surface and subsurface exploration of a site till to a defined depth (in Italy $30 \mathrm{~m}$ below the ground level) before the construction of a building. An interesting possibility concerning the association of geotechnical tests and thermal test are already available in the literature. It is particularly interesting for example the thermal cone penetration test (TCT) developed by Akrouch et al. [17]. This study uses the heat generated by friction during insertion of the cone to infer the thermal conductivity.

After a preliminary analysis of the recent evolutions of TRT, the paper aims to propose a method for estimating the thermal properties of soil in a relatively short time and in conjunction with the geological test so that the thermal properties of soils could be estimated together with other key geotechnical properties. The objective is also to understand which one of the available methodologies could be the best one in order to connect the two different tests.

\section{Definition of ground thermal properties: the advantages of experimental analysis}

A thermal response test allows direct in situ measurements of the ground thermal properties. During a TRT, the fluid circulating in a GHE is heated at a constant rate and the evolution of its temperature is monitored. The fluid temperature rise is function of the ground thermal conductivity of the borehole equivalent thermal resistance and of the heating power.

Heat transfer between the fluid circulating in a BHE and the surrounding ground is a quite complex task because of the several phenomena involved. The presence of groundwater flow superimposes convection over conduction; moreover, the groundwater level influences the moisture content of the ground, thus affecting its effective thermal conductivity.

Several criteria have been proposed in literature to find out if convective heat transfer does not allow to appreciate conductivity properties. Another problem is that the ground is generally stratified so the BHE exchanges heat with layers with different conductivity; this invalidates the assumption of constant linear heat flux, typical of conventional thermal response tests. The aforementioned effects make difficult to model the heat transfer in a borehole but fundamentally, the purpose of TRT is to obtain depth-averaged ground thermal conductivity for determining a length of GHE. The effective thermal conductivity assumption for a subsurface with different formations has already been validated in many studies.

Analytical models rely on simplifying hypotheses: ground is considered as purely conductive and homogeneous medium and the heat transfer is taken as radial (solutions of one-direction Fourier equation). Numerical models can consider these effects when simulating the thermal behaviour but when treating experimental data, it would be possible to consider stratification and groundwater influence only if their characteristics were well known and this is not the actual case. In the end, whatever model is adopted, conventional TRT gives the value of the effective ground thermal conductivity: it accounts for all the thermal phenomena occurring in the borehole and is strictly related to the depth tested.

The development of in situ tests like the thermal response test is strictly connected with the perspective of a diffused use of Ground Source Heat Pump (GSHP) systems. With respect to a design based on standard data, a design that follows a Thermal Response Test, permits to approach an optimum design of the system and consequently better performances during operation and economic design. In particular no oversized systems, in particular heat transfer surfaces, corresponds to lower investment cost for the installation. On the other hands, TRT requires not negligible costs and it is reasonable to think that in the current form, it can be recommended only for systems with minimum thermal power of $50 \mathrm{~kW}$.

But economical suitability of ground source heat pumps (GSHP) is a delicate issue. The investment is high with respect to traditional solutions so annual savings should be high enough to ensure acceptable payback time. Annual savings can be directly related to climatic conditions: it is evident that colder temperatures require a greater energy consumption and, proportionally, entail greater savings. This means the analysis of climatic conditions is essential to evaluate the convenience 
of a GSHP installation. Design is economically sensible due to the high costs related; depending on the type of exchanger as well as of the ground.

In general, it is possible to distinguish between two cases if experimental data of ground are available or not. If thermal properties of the ground are known, for example from a TRT, the knowledge of the accuracy of the data is fundamental.

Slight underestimation or overestimation of the thermal conductivity value entails significant oversizing or under sizing of the exchanger, with relevant greater investment or operating costs. Sanner et al. in [18] estimated these effects for a $50 \mathrm{~kW}$ GSHP designed for a case in which the ground thermal conductivity of value $2.2 \mathrm{~W} / \mathrm{mK}$ ground. Just an uncertainty of about $0.4 \mathrm{~W} / \mathrm{mK}$, corresponding to the $20 \%$, would entail important variation in the cost of the whole system.

Borehole resistance has also a strong impact on exchanger length and consequently on the investment cost; oversizing could result in additional expenses (Marcotte and Pasquier, [16]). Basing on such considerations, the maximum error admitted on ground thermal properties is $10 \%$.

In the last thirty years, as a consequence of the growing interest for the installation of GHP and GSHP a lot of methods for experimental tests have been submitted in literature. Two main directions are considered: the way for "quick and dirty" tests with reduced accuracy for routine design of small systems in residential houses and the way of more sophisticated tests providing more accurate data.

\section{Thermal Response Test: methodology description and theoretical analysis}

The principle of a TRT is based on the interpretation of the responses (i.e. the change in temperature of the circulating fluid at the well head) resulting from a thermal stimulation accomplished via extraction or feeding of a certain heat flow. The time-dependent behaviour of the mean fluid temperature between the inlet and the outlet of the heat exchanger represents the experimental data. The ground thermal parameters obtained from the test are:

- Effective ground thermal conductivity, $\lambda$

- Undisturbed ground temperature, To

- Thermal diffusivity of the ground, $\alpha$.

The TRT data are compared with analytical solution or numerical results. The Finite Line Source Model solution, which account for the finite dimension of the heat source, is often used to restore the soil thermal conductivity.

Several authors, suggested different experimental procedures and models in order to improve the accuracy of TRT and to shorten the test time. First experiences of thermal response tests as a method for determining in situ values of ground thermal conductivity and thermal resistance in BHE systems have been carried out by Mogensen in 1980s, [19].

An important activity has been carried out in Sweden at University of Lulea (Eklöf and Gehlin, in [20]) and at the University of Oklahoma (Austin in [21]). Conventional thermal response tests, those currently done on a commercial basis, rely upon these first schemes (see Figures 1 and 2).

A heat exchanger is installed in the ground (it will be part of the final installation) and connected to the test rig which mainly contains a heating and/or a chilling device and a circulation pump; linking piping has to be insulated and shielded. The exchanger is then filled with water or a mixture of water and anti-freezing fluid through the rig. Measures are taken by thermometers installed at the borehole wellhead.

In the first phase of the test the fluid is circulated without heat injection or extraction so to determine the undisturbed ground temperature; the correct duration of this part of the test has been discussed by Gehlin and Nordell in [22].

In the second phase the electrical resistance or the chiller is switched on and the fluid starts exchanging heat with the ground. The thermal response of the ground is taken as the arithmetic mean of the inlet and outlet temperature measured; experimental data are finally used in a heat transfer model to estimate ground thermal conductivity and borehole resistance. The cost of the test is strictly connected to the penetration depth and to the long time required, which depends on the long time 
for the thermal perturbation to reach the undisturbed ground; the length usually advised in literature is of 50 hours for obtaining error on thermal conductivity below $10 \%$ (see Figure 3).

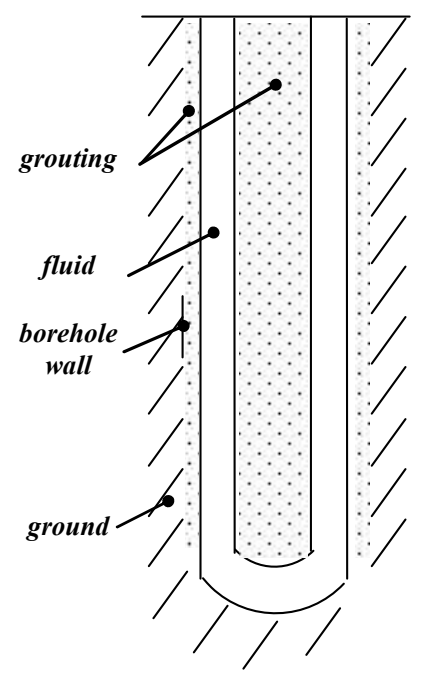

Figure 1. Nomenclature for Thermal Response Test (TRT).

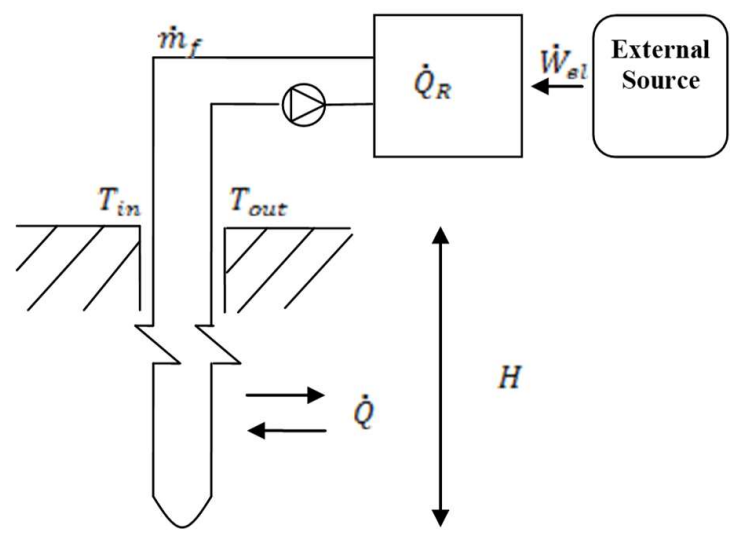

Figure 2. Typical conceptual schematization of a Thermal Response Test.

Moreover, the test is sensitive to the deep of the borehole. The heat transfer between fluid circulating in a BHE and ground is quite complex, due to different phenomena involved:

- the presence of groundwater flow superimposes convection over conduction; moreover, the groundwater level influences the moisture content of the ground, thus affecting its conductivity. Several criteria have been proposed in the literature for considering this problem (Signorelli et al., [12], Witte et al., [23]).

- the ground is generally stratified so the BHE exchanges heat with layers with different thermal conductivity; this invalidates the assumption of constant linear heat flux, typical of conventional thermal response tests;

- the heat is mainly transferred in radial direction; in addition to that, effects like geothermal gradient, finite length of the exchanger and thermal short circuit entail an axial heat flux. 

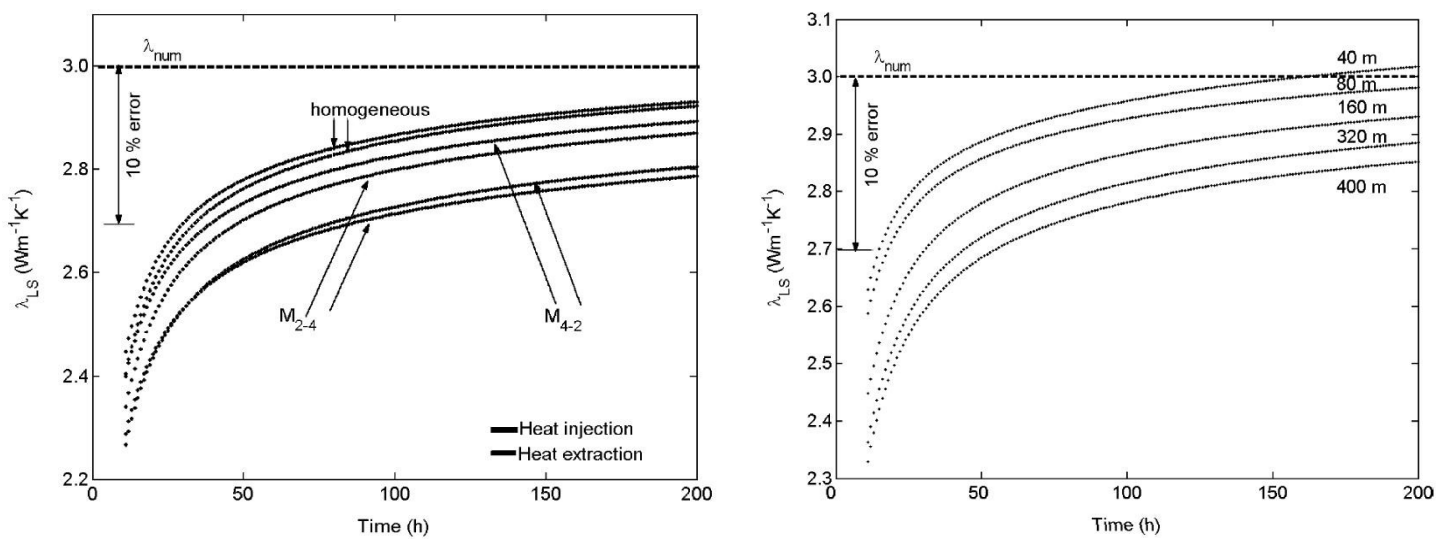

Figure 3. Calculated thermal conductivities based on the line-source model, $\lambda_{\mathrm{LS}}$, for different borehole lengths and time duration [graphics from Signorelli et al. [12].

All these effects make difficult the modeling of the heat transfer in a borehole. Analytical models rely on simplifying hypotheses: ground is considered as purely conductive and homogeneous and the heat transfer is taken as radial (solutions of 1-D Fourier equation). Numerical models can consider these effects when simulating the thermal behaviour but when treating experimental data, it would be possible to consider stratification and groundwater influence only if their characteristics were well known and this is not the actual case.

In the end, whatever model is adopted, conventional TRT furnish an estimation of the value of the effective ground thermal conductivity: it accounts for all the thermal phenomena occurring in the borehole and is strictly related to the depth tested $(\mathrm{H})$. Analytical models to compute conductive heat transfer in a borehole and the subsurface during a TRT are based on solutions of the Fourier equation; they therefore assume the ground to be a homogeneous and isotropic medium. The classical models adopted are one-dimensional, thus neglecting axial effects. The solution of the conductive problem is used to relate the temperature of the ground at the borehole wall and that of the undisturbed ground, i.e., to derive the g-function (introduced in [24])

$$
T_{B}(t)-T_{0}=\frac{q^{\prime}}{2 \pi \lambda_{g}} g\left(t^{*}\right)
$$

The thermal response is then related to the borehole wall temperature by the thermal resistance $\mathrm{R}_{\mathrm{B}}$, accounting for the heat transfer phenomena inside the borehole (pipes and grouting, being valid the hypothesis of a steady state conduction inside the borehole):

$$
\bar{T}_{f}-T_{B}=q^{\prime} R_{B}
$$

Finally, the two conductive problems can be unified so that

$$
\bar{T}_{f}(t)=T_{0}+\frac{q^{\prime}}{2 \pi \lambda_{g}} g\left(t^{*}\right)+q^{\prime} R_{B}
$$

The simplest and more used analytical model for the analysis of TRT results is the infinite line source one (Carslaw and Jaeger, [25]). In this case the ground is taken as an infinite medium and the exchanger is an infinite line source with constant linear power. The method gives the radial temperature distribution as a function of time; the thermal field for this system (hence the g-function), depending only on the radial coordinate, is given by

$$
\bar{T}_{f}(r, t)=T_{0}+\frac{q^{\prime}}{2 \pi \lambda_{g}} \int_{\frac{r^{2}}{4 \alpha t}}^{\infty} \frac{e^{-u}}{u} d u \approx T_{0}+\frac{q^{\prime}}{4 \pi \lambda_{g}}\left[\ln \frac{4 \alpha t}{r^{2}}-\gamma\right] \rightarrow g\left(t^{*}\right)=\frac{1}{2} \cdot\left[\ln \frac{4 \alpha t}{r_{B}^{2}}-\gamma\right]
$$


For the infinite line source Eq. (4) becomes

$$
\bar{T}_{f}(t)=T_{0}+q^{\prime}\left[R_{B}+\frac{1}{4 \pi \lambda_{g}}\left(\ln \frac{4 \alpha t}{r_{B}{ }^{2}}-\gamma\right)\right]
$$

This case allows an immediate evaluation of the ground thermal conductivity or the thermal diffusivity since there is a direct proportionality between the thermal response and the time $t$. Once that this property is known, the borehole wall temperature is calculated by Eq. (1) and used in Eq. (2) to define the borehole resistance $R b$.

The method is diffusely proposed in the literature for the measurement of the thermal conductivity and thermal diffusivity of fluid and solid materials; a possible application is described by one of the author of the paper in [26].

Other quite spread models are the infinite and the finite cylinder source models, that differ from the line source for the shape of the heat source even if the results are not appreciably different if the length is quite high. Despite their higher precision in describing the physical system, the results given are very close to the line source ones thus not justifying the quite high computational cost required (as discussed by Lamarche and Beauchamp in [20]).

The use of numerical models can be another choice for the analysis of experimental data. There are several kinds of 1D, 2D or 3D models in the literature; they provide a better description of the system and investigate axial effects, but their full potentialities can be exploited only in direct problems: for example, they can manage power variations, but these are due to external interactions and/or electrical fluctuations, so they are neither predictable nor assessable; Signorelli et al., [12]. A quantitative difference between the results obtained with the two models is summarized in Figure 4. As it can be observed, after 50 hours the difference appear to be constant and less than $5 \%$.

\section{Mathematical model for TRT data analysis: the finite line source method}

Finite line source model is widely used for the interpretation of TRT data because of its simplicity. Solving the Fourier equation with the conditions (see Figure 4)

- $\Delta \mathrm{T}_{\text {geo, }}$ is uniform;

- $\quad \dot{\boldsymbol{q}}$ is constant with depth;

- $\quad \boldsymbol{T}_{\boldsymbol{s}}=\boldsymbol{T}_{\mathbf{0}}$, is constant during time.

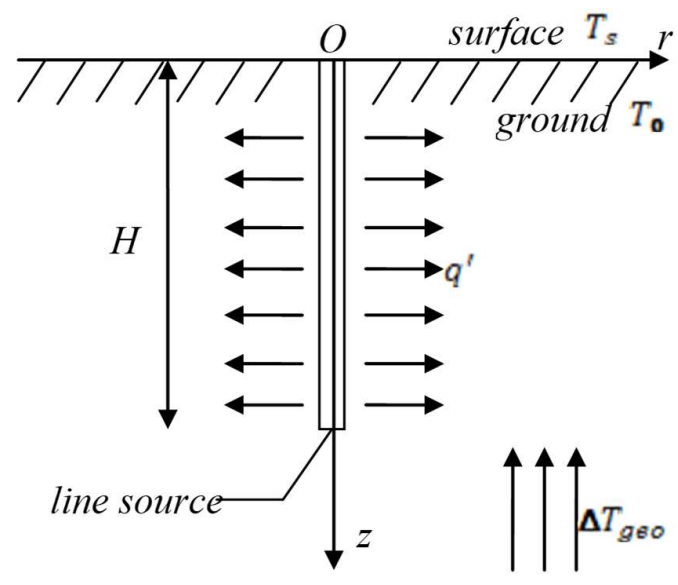

Figure 4. Scheme for the modelling of TRT with finite-line source method.

The solution of the conductive problem already discussed can be expressed in the form of Eq. (1). Assuming the validity of the model, the differences with respect to the infinite can be first of all connected with the expression of the g-function. Eskilson and Claesson, in [20] proposed the relation: 


$$
g(t, r, z)=\frac{1}{2 \pi} \int_{0}^{H}\left[\frac{\operatorname{erfc}\left(\frac{\sqrt{r^{2}+(z+h)^{2}}}{2 \sqrt{\alpha t}}\right)}{\sqrt{r^{2}+(z-h)^{2}}}-\frac{\operatorname{erfc}\left(\frac{\sqrt{r^{2}+(z+h)^{2}}}{2 \sqrt{\alpha t}}\right)}{\sqrt{r^{2}+(z+h)^{2}}}\right] \cdot d h
$$

The g-function for this model can be solved numerically or available in tabular form. To analyze the results of TRT it is desirable to have an analytically-manageable g-function for a more practical use in the design procedures: tables are referred to specific borehole dimensions and configurations. Eskilson and Claesson tried to approximate their results taking the borehole temperature at the middle depth (thus fixing the axial coordinate); this resulted in a simple g-function which however turned out to overestimate the mean borehole temperature. Zeng et al., [13] worked on the problem and proposed a new form of the g-function based on the integral mean of the borehole wall temperature which did not result easier to be solved. But it has been the starting point for the elaboration of Lamarche and Beauchamp in [14] who transformed it from a double integral form to a two single integrals form in using the complementary error function:

$$
g\left(\frac{t}{t_{s}}, \frac{r_{B}}{H}\right)=\int_{\beta}^{\sqrt{\beta^{2}+1}} \frac{\operatorname{erfc}(\theta z)}{\sqrt{z^{2}-\beta^{2}}} d z-\int_{\sqrt{\beta^{2}+1}}^{\sqrt{\beta^{2}+4}} \frac{\operatorname{erfc}(\theta z)}{\sqrt{z^{2}-\beta^{2}}} d z-D_{A}-D_{B}
$$

Where the three dimensionless parameters $\theta, D_{\text {А }}$ and Dв $_{\text {в }}$ are present, defined respectively as

$$
\begin{gathered}
\theta=\frac{3}{2 \sqrt{t / t_{s}}} \\
D_{A}=2 \sqrt{\beta^{2}+1} \cdot \operatorname{erfc}\left(\theta \sqrt{\beta^{2}+1}\right)-\frac{3}{2} \beta \operatorname{erfc}(\theta \beta)-\frac{\left(e^{-\theta^{2}\left(\beta^{2}+1\right)}-e^{-\theta^{2} \beta^{2}}\right)}{\beta \sqrt{\pi}} \\
D_{B}=\sqrt{\beta^{2}+4} \cdot \operatorname{erfc}\left(\theta \sqrt{\beta^{2}+1}\right)-\frac{\left(e^{-\theta^{2}\left(\beta^{2}+1\right)}-0.5 \cdot\left(e^{-\theta^{2} \beta^{2}}+e^{-\theta^{2}\left(\beta^{2}+4\right)}\right)\right)}{\beta \sqrt{\pi}}
\end{gathered}
$$

In a different analysis, Bandos et al. in [14] focused on vertical effects, considering the geothermal gradient and the variation of the surface temperature on the Fourier equation's solution. Referring to Fig. 5, the conditions given are:

$$
\Delta T_{\text {geo }} \neq 0 \rightarrow T_{g}=f(z) \quad T_{S}=\sigma(t)
$$

The g-function obtained can be approximated, according to the time scale with the two eqs.

$$
g\left(\frac{r}{H}, t\right)=\frac{1}{2}\left[-\gamma+\ln \left(\frac{4 \alpha t}{H}\right)+\frac{3 r}{H}-\frac{3}{\sqrt{\pi}} \frac{\sqrt{4 \alpha t}}{H}-\frac{3}{\sqrt{\pi}} \frac{r}{H} \frac{r}{\sqrt{4 \alpha t}}\right] \quad \text { if } \quad \frac{r^{2}}{\alpha} \leq t \leq \frac{H^{2}}{\alpha}
$$




$$
g\left(\frac{r}{H}, t\right)=\frac{1}{2}\left[-2+2 \ln \left(\frac{H}{r}\right)+\frac{3 r}{H}\right] \quad \text { if } \quad t \geq \frac{H^{2}}{\alpha}
$$

Analyzing Eq. (13) it is possible to observe that this solution approximates the infinite line source one as $H \rightarrow \infty$; this demonstrates that finite length has a real impact on the thermal response on the medium-long term only, anyway for time intervals longer than the normal duration of a TRT, as also discussed by Lamarche and Beauchampe, in [14].

\section{Thermal Response Test: analysis of recent innovative concepts}

Conventional TRT version analyzed in the previous section results to be a quite simple method for ground thermal characterization, even if it presents some serious weak points. In particular, the main drawback is represented by the quite high cost is too high relatively to the results expected and the time required to complete the analysis. Some innovation in the matter appears to be quite interesting. In the following pages different version of the TRT are analyzed and reviewer with the objective of identifying which one can be adapted to possible standard in-situ test.

\subsection{Thermal response test while drilling (TRTWD)}

TRTWD is a particularly interesting method for the execution of Thermal Response Tests based on the utilization of information obtainable by the fluid drilling of the borehole even if it uses the same basic principle as standard TRT measurement. The method has been discussed by Tuomas and Gustafsson in [27]. The head of the hammer perforating the ground dissipates energy, partly transferred to the string fluid and partly to the ground; the working principle is to measure the inlet and outlet drilling fluid temperature in order to determine the thermal conductivity profile in the ground. Data are analyzed by means of a numerical code but the analysis is based on the energy conservation equations. A major advantage compared to standard TRT is that this method would give a "continuous value" of the thermal conductivity along the borehole instead of a mean value. The disadvantage is that the borehole resistance is not evaluated, instead it is a standard value used for the given borehole configuration.

\subsection{Enhanced thermal response test (eTRT)}

This is a technique has been industrially developed. It is possible to find some details about the method in the papers from Poppei et al., as [4] and [28]. A small wireless submergible probe called NIMO-T can be lowered in boreholes to measure pressure and temperature profiles. The undisturbed ground temperature profile, known together with the axial heat flux, allows the definition of the thermal conductivity. This cannot be done directly because the axial heat flux is variable due to local phenomena (geothermal anomalies, shallow fluctuations induced by variation of superficial temperature, etc.). For this reason, NIMO-T probe is used in association with a conventional TRT: the probe is used to measure temperature profiles before the test, just after its execution and one or two days later. An appropriate numerical model simulates thermal responses and matches them with the measured ones by varying ground properties. Diagnostic plots are techniques typical of hydrogeological investigations transferred to the thermal applications on the basis of the mathematical similarity between Darcy and Fourier equations.

The method appears to be completely different from conventional one: while latter ones tend to minimize external interference with the fluid, this method eliminates insulation of the external piping and every device for thermal supply; fluid exchanges heat with the ground and the external air (that acts as the heat source/sink). Variables measured are the mass flow rate (considered as a constant) and the inlet and outlet temperature of the fluid. Interpretation of data is based on a convectiveconductive analytical model. It consists of a linear undisturbed ground thermal profile with geothermal gradient $\omega$, a fluid thermal profile, superficial and sub-superficial heat transfer, described by the parameter $a$ 


$$
T_{b h}(t)=e^{-a H}\left[T_{s}\left(t-t^{\prime}\right)+\omega z+\frac{1-e^{-a H}}{\alpha\left(\alpha T_{0}-\omega\right)}\right]-\omega H+\frac{1-e^{-a H}}{a}\left[\alpha\left(T_{0}+\omega H\right)+\omega\right]
$$

Since flow and borehole filling characteristics are known, $\alpha$ is the only unknown variable with respect to the ground conductivity that can be determined by best fitting the ground thermal conductivity value.

\subsection{Distributed thermal response test (DTRT)}

DTRT is a conventional thermal response test in which fluid temperature is not measured at the borehole head but along the entire exchanger by an optical fiber cable (referring to Raman effect). Measurements are not continuous: they are taken at certain depths and at different time resolution, both during the test execution and the thermal recovery phase. Data can be then analyzed by an infinite line source, as discussed by Acuña et al., in [5], or using the approximation of an infinite cylinder source, as proposed by Fujii et al., in [6]. This technique allows obtaining a vertical profile of the ground conductivity and, when infinite line source is used, of the borehole resistance.

\subsection{Constant heating temperature method (CHTM)}

The version of the method called CHTM utilizes a rig similar to those used for normal tests with the possibility to choose between heat injection and extraction. The temperature of the inlet fluid is defined and controlled regulating the chilling or heating devices. The main elements of the method can be obtained in the paper by Wang et al., [8]. The main idea is the direct proportionality between the mean fluid temperature and the linear power exchanged in steady state conditions:

$$
\frac{q_{S S}^{\prime}}{\bar{T}_{f, S S}}=K
$$

In this way, the borehole temperature can be defined as

$$
T_{B}=\bar{T}_{f, S S}-q_{S S}^{\prime} \cdot R_{B}=\bar{T}_{f, S S}\left(1-K R_{B}\right)
$$

and finally applying a particular g-function, the ground thermal conductivity can be obtained as:

$$
\lambda_{g}=\frac{g K}{2 \pi\left(1-K R_{B}\right)}
$$

\subsection{Thermal response test using heating cables, (HC-TRT)}

This particular version of the method has been proposed by Raymond et al. in [9]. In this case thermal power is transferred to the fluid directly inside the borehole by means of electrical heating cables. The fluid is still in the exchanger and temperatures are measured along the vertical profile by thermistors. There are two phases: in the first one, lasting 50 hours circa, power is dissipated in the cables while in the second one, lasting about 50 hours, the ground is left in thermal recovery. Temperatures utilized for the thermal characterization of the ground are those measured in the recovery phase, which can be analyzed theoretically by means of the infinite line source model

$$
\bar{T}_{f}(t)=T_{0}+\frac{q^{\prime}}{2 \pi \lambda_{g}}\left[\ln \frac{4 \alpha t}{r_{B}{ }^{2}}-\ln \frac{4 \alpha\left(t-t_{\text {off }}\right)}{r_{B}{ }^{2}}\right]=T_{0}+\frac{q^{\prime}}{2 \pi \lambda_{g}}\left[\ln \left(\frac{t}{t-t_{\text {off }}}\right)\right]
$$

or by means of numerical analysis. 


\subsection{Thermal cone dissipation test, (TCT)}

Akrouch et al. in [17] presents a new test, called the thermal cone dissipation test (TCT), as insitu technique to determine the thermal properties of soils. The proposed technique expands the capabilities of the well-known geotechnical method known as cone penetration test (CPT), used for defining structural quantities to deal with thermal measurements.

The equipment consists of a cone penetrometer equipped with thermocouples located behind the cone point. The TCT is pushed in the ground at the standard penetration rate of $2 \mathrm{~cm} / \mathrm{s}$, and the friction between the cone and the soil increases the cone temperature. The temperature decay is recorded as a function of time (for approximately $30 \mathrm{~min}$ ): this information is used to estimate the thermal conductivity and other thermal properties of soils.

The TCT does not require a heater to induce the thermal perturbation in the ground, but relies on the heat naturally generated by the friction between the cone and soil during penetration to induce the thermal perturbation in the ground.

The proposed apparatus records (by means of thermocouples) the temperature at the contact between the cone and the surrounding soil. The decay of the temperature in time is used to estimate the thermal conductivity of the ground. The idea developed is really interesting even if the power generated during the penetration strongly depends on the type of soil.

The several alternative TRT methods proposed in order to prevent some drawback of the basic method are summarized in Table 1, in which an attempt is made to summarize the peculiarities of each one.

Table 1. TRT methods available: nomenclature and characteristics.

\begin{tabular}{|c|c|c|}
\hline Method name & Positive or negative peculiarities & Main references \\
\hline Thermal response test (TRT) & $\begin{array}{l}\text { Time consuming: the standard test requires } \\
\text { more than } 100 \text { hours in order to achieve } \\
\text { accurate results }\end{array}$ & $\begin{array}{l}\text { Eklöf and Gehlin,, [20]); } \\
\text { (Austin, [21] }\end{array}$ \\
\hline $\begin{array}{l}\text { Thermal response test while drilling } \\
\text { (TRTWD) }\end{array}$ & $\begin{array}{l}\text { A "continuous value" of the thermal } \\
\text { conductivity along the borehole instead of a } \\
\text { mean value is furnished }\end{array}$ & $\begin{array}{l}\text { (Tuomas and } \\
\text { Gustafsson [7], [27] }\end{array}$ \\
\hline $\begin{array}{l}\text { Enhanced thermal response test } \\
\text { (eTRT) }\end{array}$ & $\begin{array}{l}\text { Affected by errors due to the axial heat flux, } \\
\text { variable due to local phenomena (geothermal } \\
\text { anomalies, fluctuations induced by } \\
\text { temperature variation, etc.) }\end{array}$ & $\begin{array}{l}\text { Poppei et al., [3] and } \\
[28])\end{array}$ \\
\hline $\begin{array}{l}\text { Distributed thermal response test } \\
\text { (DTRT) }\end{array}$ & $\begin{array}{l}\text { Fluid temperature is measured along the } \\
\text { entire exchanger by an optical fiber cable }\end{array}$ & $\begin{array}{l}\text { (Acuña et al., [5]); (Fujii } \\
\text { et al., [6]) }\end{array}$ \\
\hline $\begin{array}{l}\text { Constant heating temperature } \\
\text { method (CHTM) }\end{array}$ & $\begin{array}{l}\text { Two phases of the test: injection mode and } \\
\text { other extraction mode at different inlet fluid } \\
\text { temperatures }\end{array}$ & Wang et al., [8] \\
\hline $\begin{array}{l}\text { Thermal response test using } \\
\text { heating cables, (HC-TRT) }\end{array}$ & $\begin{array}{l}\text { Two phases of the tests: total duration about } \\
100 \text { hours }\end{array}$ & Raymond et al. [9] \\
\hline $\begin{array}{l}\text { Thermal cone dissipation test, } \\
(T C T)\end{array}$ & $\begin{array}{l}\text { The duration of the test is very low: about } 30 \\
\text { min. TCT is performed in conjunction with } \\
\text { the cone penetration test so that the thermal } \\
\text { properties of soils are estimated with other } \\
\text { key geotechnical properties }\end{array}$ & Akrouch et al. [17] \\
\hline
\end{tabular}

\subsection{Discussion}

Considering the various methods tested for ground thermal characterization, the TRTWD appears to be a very interesting one since it would allow to have a vertical profile of thermal conductivity and to lower the cost of the test. It just requires to make measurements during the perforation of the borehole. Obviously, borehole resistance cannot be assessed by this method but it 
could be evaluated by empirical formulas or using known values for standard configurations. But it is not easy the practical application of this technique: the solution of the direct problem shows that temperature changes of the string fluid with different conductivity grounds are extremely small; the execution of the TRTWD would require quite high precision temperature measurement (Gustafsson and Nordell in [27]). Moreover, there would be operational problems: instruments could be disturbed by dust and vibrations generated by the ongoing perforation. The idea of TRTWD has been not so really developed in the last years, but it presents various advantages with respect to a conventional TRT: the rig is very simple; moreover, the mathematical model is directly referred to the mean temperature between inlet and outlet and, due to its simplicity, permits a fast analysis of the data. Negative aspects of this method are the fact that ground temperature profile is taken as linear, without considering the impact of external conditions on the shallow zone; on the other side, signals from the deep zone are not received at the borehole head because of the small temperature differences between the fluid and the ground.

Considering the other methods, it is possible to understand that CHTM method has more drawbacks than advantages: this method contemplates to shorten the test length and eventually requires more time than a conventional TRT, with even less complete results. While Wang et al. in [8] underline the faster approach to the steady state of CHTM versus a traditional TRT, they just pass over the fact that four executions of the test are at least needed which means a longer duration, even without considering the dead time for the thermal recovery of the ground between one test and another. Moreover, the result given is a simple mean effective conductivity; borehole resistance is needed as an input data.

The other three methods analyzed appear to be more meaningful in the perspective of a future development of TRT tests.

The eTRT procedure seems to be a good method that gives a vertical profile of conductivity. Nevertheless, considering the analysis by Poppei et al., [4], it is not clear the validity of the numerical interpretation of data: it has been shown a good agreement when evaluating a single layer only so it is not demonstrated whether the conductivities of the different regions are correlated or not; it is important to have a strong unambiguousness of the data with the conductivity profile, otherwise results would have the same usefulness of a mean value. Diagnostic plots are a truly effective new concept in the interpretation of TRT data: their strength is not the conductivity given but the monitoring of the test progress, which allows the optimization of the test duration and economical savings. Calculations needed are not complex so their application is advised for whatever kind of TRT is performed. The version of the TRT called DTRT appears to be promising: the future perspective of TRT is surely to have a vertical profile of conductivity and borehole resistance, at least for bigger installations; these enable the optimization of the design and constitute a further perspective for possible improvements. Regarding the interpretation of data, infinite line source as proposed by Acuña et al. [5] seems to be better than the cylinder source model which turns out to be a complex iterative procedure not even giving borehole resistance as result. Nevertheless, some issues still have to be assessed:

- the minimum duration of such test is not clear, as only experimental tests are present in literature;

- optical fiber thermometers have not a high sensibility or accuracy so attention should be paid to the spatial resolution of measurements (a minimum of 10 meters is advised);

- $\quad$ since the length of the source is reduced, it could be interesting to investigate whether is better to make use of a finite line source theory for the interpretation of data.

Finally, HC-TRT appears to be an innovative method both for what concerns its test rig and for the test execution; its advantages with respect to a conventional TRT are: 
- the power exchanged between the fluid and the ground is more constant and uniform since heat is generated directly inside the borehole; this fits with the hypothesis of analytical models, resulting in a more accurate test;

- dimensions and weight of the rig are largely reduced;

- temperatures can be measured along the borehole depth obtaining a conductivity profile.

Notwithstanding this, HC-TRT presents some intrinsic weak points:

- data from the heat injection phase are useless so measurements are to be taken during the recovery period: this increases the test length, which eventually is circa twice the TRT one. According to Raymond et al., [6], this test can be fully automatized resulting time efficient.

- borehole resistance cannot be assessed. This finally seems to be a common trend: besides, values for standard configurations are known and empirical formulas are available in literature.

Concerning the developments of analytical models, it is clear that finite line source methods cannot improve a TRT results simply because its duration does not allow to appreciate any difference between this model and the infinite length version. Nevertheless, it would be interesting to compare the interpretations of the same data set with the two models to prove this experimentally. Moreover, the finite line source model could be useful for the analysis of long term performance of GSHP and interactions among the boreholes of a huge installation.

\section{Connection of TRT and geological test: possible way for standardization and widespread use}

As discussed in the previous section a different number of in-situ tests based on thermal probes instrumented with thermocouples have been proposed in the literature for determining the soil thermal properties in different applications and to prevent some drawbacks of the standard TRT methods. As it was discussed there are different peculiarities that provides interesting element in each one of the methods. In this section the intention of the authors is to propose a new method that try to join the positive qualities of the most interesting proposal available in the literature.

Nowadays TRT is carried out only for installations in which a priori estimate requires a certain number of BHEs. TRT results can be used, together with the thermal loads required by the installation, to calculate the total exchanger length required. According to the basic relation given in the handbook by ASHRAE, [29], the length of the pipe can be related to the various external parameters by the following equation:

$$
L=\frac{q_{y} R_{g, y}+\left(q_{c}-W_{e l}\right) \cdot\left(R_{B}+P F L_{m} \cdot R_{g, m}+R_{g, d} F_{s c}\right)}{T_{0}-T_{h p}-T_{p}}
$$

In this equation, the borehole resistance is explicitly used while the ground conductivity is indirectly used to define the three thermal resistances $R_{g, y} ; R_{g, m} ; R_{g, d}$; in particular these resistances are proportional to $\lambda_{g}^{-1}$, [30]. The design procedure is iterative: once the total length $\mathrm{L}$ is known, the designer chooses how many exchangers to use and, re-determines on this basis the interference temperature, $T_{P}$, and verifies once more the total length, as discussed in [14].

This project routine is incoherent with the use of the ground conductivity as given by a conventional TRT, since it is an effective property of the ground and is strongly related to the depth tested. Methods giving a single value of conductivity limit the design flexibility since the length calculated by Eq. (19) must be divided in a number of BHE of equal length as the one tested; in this way, the only variable results to be the number of exchangers and their disposition in the field.

In order to optimize the design (in terms of number of exchangers/length of exchangers) it seems interesting to propose to characterize the ground by vertical profiles of conductivity, using a concept 
like Distributed Thermal Response Test (DTRT) associated with line source evaluation. Moreover, it is advised to compare the results given by an infinite and a finite line source method in order to evaluate the impact of finite length effects: even if in the foregoing these seem to affect only the long term behaviour of the borehole, according to Signorelli et al., [12], these could be detected in the short term too. TRT is not usually done for smaller installations for economic reasons; it is anyway preferable a method that would allow to avoid oversizing in this case too. The only way to achieve this is of course lower the cost of the test itself, making it convenient. The duration of the test cannot be decreased significantly as it has an intrinsic lower limit; it can be at most optimized by means of techniques such as the diagnostic plots. GSHPs are usually made for new built buildings as they work well with low temperature heating systems. Considering that the major expense for a TRT is the borehole perforation, it is reasonable to think about an integration between geotechnical and thermal surveys.

In earthquake-prone countries like Italy, where seismic events often cause heavy damage to residential and public buildings vulnerability assessment of buildings plays an important role both to define suitable timescales for the strengthening interventions (dealing with large scale programs) and to choose effective retrofit strategies. The first step in assessing vulnerability is the knowledge of the mechanical properties of the constituent materials. The current European and Italian seismic codes [31,32] requires preliminary investigation.

During the past decades, experiences with the behavior of slopes, and often with their failure, have led to development of improved understanding of the changes in soil properties that can occur over time, have determined the development of new and more effective types of instrumentation to observe the behavior of slopes, improved understanding of the principles of soil mechanics that connect soil behavior to slope stability. [33].

As a matter of fact, in Italy, new buildings require a prospecting for the assessment of geological and seismic properties of the ground; for example, in Italy D. M. 14th of January 2008, "Technical Norms for Constructions" requires the Indication of the category of foundation soil. The definition of the foundation soil category requires the execution of in situ geotechnical tests largely available today as Standard Penetration Test (SPT), or Cone Penetration Test (CPT), Sismic Prospecting in hole (Down-hole or Cross-hole) or other tests near the center of gravity of the building. The peculiarities of those method are exposed in [17]. The idea here submitted is to install a testing exchanger in the borehole (of 30 meter) and apply a Heating Cable Thermal Response Test (HC-TRT) or otherwise a classical TRT with an auxiliary fluid using only the 30 meters available: in this case it is extremely important to optimize the parameters (diameter of the pipe, mass flow rate of the fluid, inlet temperature) in order to obtain a fast stabilization of the efficiency curve. HC-TRT has the advantage of simple rig and testing procedure: this is important in the perspective of the transfer of all the duties to a single company, that is the geotechnical one. Obviously, the conductivity given by such a test would be referred to the limited depth of 30 meters; since the number of BHE to be installed is small, the approximation of constant conductivity with depth is valid, unless there is a relevant groundwater flow deeper in the ground. On the other hand, from the analysis of Signorelli et al., [12], referred in Figure 3 it appears that at a length of $30 \mathrm{~m}$ the time of 30 hours could represent a good compromise between accuracy and simplicity of the test. The method proposed can be based on the "infinite line source" or alternatively on the "finite line source" model and on the $\varepsilon$-NTU method for the operation of the heat exchanger [34]. Measuring the inlet and outlet temperature of the fluid and the mass flow rate at a well-known surface of the BHE an average heat transfer coefficient can be estimated from the heat transfer effectiveness, $\varepsilon$, as:

$$
\varepsilon=\frac{T_{\text {in }}-T_{\text {out }}}{T_{\text {in }}-T_{g}}=1-\exp (-N T U)
$$

where NTU is the Number of Transfer Units. According to the model of the infinite line source, referred with Eq. (5), $U A$ can be expressed as: 


$$
U A=\frac{H}{\left\{R_{B}+\frac{1}{4 \pi \lambda_{g}}\left[\ln \left(\frac{4 \alpha t}{\left(3,5 r_{p}\right)^{2}}\right)-\gamma\right]\right\}}
$$

where $\mathrm{H}$ represent the bore depth (i.e., $30 \mathrm{~m}$ ), $\mathrm{t}$ is the time required for the experiment and assuming the following relation is assumed between borehole radius (

$$
r_{B}=3.5 r_{P}
$$

Considering the typical values of soil thermal diffusivity $\left(10^{-6} \mathrm{~m}^{2} / \mathrm{s}\right.$ for example) after a sufficiently long time so that the logarithmic term could be comparable with Euler constant, thus, the relation between NTU, the ground thermal conductivity $\lambda_{\mathrm{g}}$, and the borehole resistance becomes:

$$
\frac{N T U}{H}=\frac{1}{\rho \pi r_{i}^{2} v c\left\{R_{B}+\frac{1}{4 \pi \lambda_{g}}\left[\ln \left(\frac{4 \alpha t}{\left(3,5 r_{p}\right)^{2}}\right)-\gamma\right]\right\}}
$$

In this way, an indirect estimation of the thermal conductivity can be obtained. According to the ideas contained in the literature concerning the TRT-HC, the test can be proposed in the two possible versions: heating mode or cooling mode.

Case 1: Test in cooling mode

In this case the inlet temperature of the fluid is higher than the temperature of the ground. Measurement of temperature of the ground and of inlet and outlet temperature can be correlated to the NTU of the heat exchanger, or to the mean heat transfer coefficient $U$ according to the equation:

$$
N T U=\ln \frac{\left(T_{\text {out }}-T_{g}\right)}{\left(T_{\text {in }}-T_{g}\right)}=\frac{U A}{m c_{p}}
$$

Case 2: Test in heating mode

The case is similar to the previous one with the difference that the inlet temperature of the water is lower than ground temperature so that the fluid is heated. In this case it is

$$
N T U=\ln \frac{\left(T_{g}-T_{\text {in }}\right)}{\left(T_{g}-T_{\text {out }}\right)}=\frac{U A}{m c_{p}}
$$

In both the cases, the velocity of water can be maintained in the range between 0,5 and $1,3 \mathrm{~m} / \mathrm{s}$ while the outer pipe diameter goes from 3.2 to $4.0 \mathrm{~cm}$. In any case, a turbulent regime should be ensured within the duct. Regarding the rig, it would be interesting to evaluate the feasibility of a version of the TRT like the HC-TRT using fluid circulation instead that a heating cable. The complication of the device would result in the possibility of getting information about the borehole resistance. With respect to the layout presented in [9], a circulation pump and an expansion vessel are necessary and the loop should be closed by thermally insulated and shielded pipe (Figure 5). 

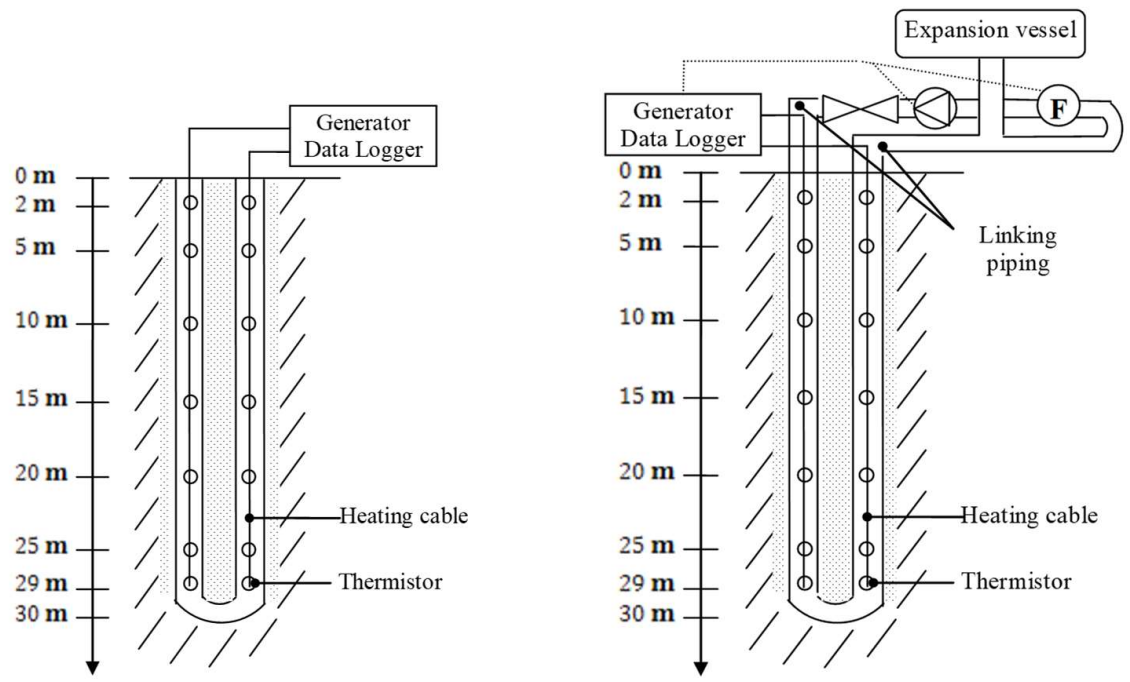

Figure 5. Schematization of the Standard Routine Test.

The measurement scheme would be the same, independently of the rig used. This layout aims to the possibility of evaluating either a mean conductivity or the conductivity for $2-3$ layers; two couples of thermal sensors (eg. Thermocouples or thermistors), located at 2, 5, 25 and 29 meters of depth, permit to evaluate the impact of superficial effects and possible conductivity variations at the borehole bottom. The choice of using thermocouples as thermal sensor is due to the tight spatial resolution of measurement points: temperature difference between one and another will be small therefore sensible thermometers are required. Data can be analyzed with an infinite line source approach; as explained in Eqs. 20-25. It is also possible to compare the results of the same set of data with those of the finite line source model in order to evaluate the accuracy of the infinite line source model with this system, characterized by very limited length. If the test is run with circulation of fluid and only mean values are searched (i.e. only temperature sensors at the head of the borehole are installed), it is strongly advised to make use of p-linear temperature average introduced by Marcotte and Pasquier in [16] since it achieves a greater accuracy of the results with a minimum computational effort.

The method proposed has some advantages with respect to existing methods. The idea of estimating the thermal properties of soils are together with other key geotechnical properties typical peculiarity of the CPT is maintained. The relatively short time necessary to perform a measurement however not over the mandatory drilling phase, typical of TRTWD method, is considered. But the introduction of the thermal systems would surely increase the accuracy of the results obtained with respect to a method like the TCT.

\section{Conclusions}

In the present paper some recent results connected to the application of TRT method for thermal characterization of grounds have been analyzed and revised. The evolution of the basic method is in particular analyzed with the perspective of increasing the future application of the procedure. Different addresses can be seen in the future development:

- improvement of accuracy and gathering of vertical profiles of the thermal properties, needed in the perspective of the design optimization. In order to do this, the design scheme should also be reviewed;

- lowering of costs, with even lower accuracy, for the application of TRT techniques for smaller installations, in order to limit the oversizing of these applications due to the application of approximate rules-of-thumbs.. 
Considering the fact that to accurately and easily quantify soil thermal properties has become even more important the idea is that the thermal properties of ground can be estimated together with other key geotechnical properties typically obtained from mandatory tests. For this reason, after an analysis of the recent enhanced methods for TRT and after the consideration of the main advantages and drawbacks of each method, a further method, based on the connection of TRT tests with standard geotechnical or hydrogeological tests has been proposed and discussed.

The method can be expected to be less time-consuming than other testing and theoretical methods including a conventional TRT and can be based on the application of recent proposed evolution of TRT, like the TRTWD and TRT-HC and the analysis of the data is based on the utilization of the ๑-NTU method for the analysis of the heat exchangers. Indeed, the paper suggest a possible connection of the thermal characterization of the ground with the mandatory geotechnical surveys usually performed prior to a new building construction for seismic protection. The proposed method could be suitable for a possible promotion of widespread use of TRT for design purpose. The main advantages are the possibility of estimating the thermal properties of soil in a relatively short time. Furthermore, it can be performed in conjunction with the geological test and therefore the thermal properties of soils can be estimated together with other key geotechnical properties.

Funding: This research received no external funding except for the University of Pisa.

Conflicts of Interest: The authors declare no conflict of interest.

\section{Appendix A: Nomenclature}

\begin{tabular}{|c|c|c|}
\hline A & surface & $\mathrm{m}^{2}$ \\
\hline c & specific heat of the fluid & $\mathrm{J} / \mathrm{kg} \mathrm{K}$ \\
\hline $\mathrm{F}_{\mathrm{sc}}$ & Short-circuiting factor & \\
\hline$g$ & G-function & \\
\hline $\mathrm{h}$ & depth & $\mathrm{m}$ \\
\hline $\mathrm{H}$ & borehole length & $\mathrm{m}$ \\
\hline $\mathrm{m}$ & mass flow rate & $\mathrm{kg} / \mathrm{s}$ \\
\hline $\mathrm{PLF}_{\mathrm{m}}$ & Monthly partial loading factor & \\
\hline $\mathrm{q}^{\prime}$ & Linear thermal power & $\mathrm{W} / \mathrm{m}$ \\
\hline $\mathrm{q}_{\mathrm{c}}$ & Thermal loads & W \\
\hline $\mathrm{q}_{\mathrm{y}}$ & Yearly average of the net power transferred to the ground & $\mathrm{W}$ \\
\hline $\mathrm{R}$ & Thermal resistance & $\mathrm{mK} / \mathrm{W}$ \\
\hline $\operatorname{Rg}, \mathrm{d}$ & Effective ground thermal resistance, referred to a daily thermal pulse & $\mathrm{mK} / \mathrm{W}$ \\
\hline $\mathrm{Rg}, \mathrm{m}$ & Effective ground thermal resistance, referred to a monthly thermal pulse & $\mathrm{mK} / \mathrm{W}$ \\
\hline $\operatorname{Rg}, y$ & Effective ground thermal resistance, referred to a yearly thermal pulse & $\mathrm{mK} / \mathrm{W}$ \\
\hline $\mathrm{r}$ & Radial distance & $\mathrm{m}$ \\
\hline rв & borehole radius & $\mathrm{m}$ \\
\hline $\mathrm{T}$ & Temperature & $\mathrm{K}$ \\
\hline Thp & Mean Temperature of Heat Pump Fluid & $\mathrm{K}$ \\
\hline $\mathrm{T}_{\mathrm{p}}$ & Penalizing temperature for the thermal interactions among boreholes & K \\
\hline $\mathrm{t}$ & Time & $\mathrm{s}$ \\
\hline $\mathrm{t}^{\prime}$ & Time required for a complete circulation in the plug flow hypothesis & $\mathrm{s}$ \\
\hline$t^{*}$ & Dimensionless time & \\
\hline $\mathrm{U}$ & Overall heat transfer coefficient & $\mathrm{W} / \mathrm{m}^{2} \mathrm{~K}$ \\
\hline $\mathrm{W}$ & Power & $\mathrm{W}$ \\
\hline Z & Axial distance & $\mathrm{m}$ \\
\hline$\alpha$ & Thermal diffusivity & $\mathrm{m}^{2} / \mathrm{s}$ \\
\hline$\beta$ & dimensionless radial distance $(\mathrm{r} \mathrm{B} / \mathrm{H})$ & \\
\hline$\gamma$ & Euler's constant $(=0.5772)$ & \\
\hline$\lambda$ & Thermal conductivity & $\mathrm{W} / \mathrm{mK}$ \\
\hline$\theta$ & dimensionless parameter defined by Eq. (8) & \\
\hline$\rho$ & density & $\mathrm{kg} / \mathrm{m} 3$ \\
\hline$\omega$ & Geothermal gradient & $\mathrm{K} / \mathrm{m}$ \\
\hline
\end{tabular}




$\begin{array}{ll}\text { Subscripts } & \\ 0 & \text { Undisturbed ground } \\ \mathrm{b} & \text { of the borehole } \\ \mathrm{bh} & \text { Borehole head } \\ \mathrm{el} & \text { electric } \\ \mathrm{f} & \text { Fluid } \\ \mathrm{g} & \text { Ground } \\ \text { in } & \text { at the inlet } \\ \text { off } & \text { relative to the phase in which the power is off } \\ \text { out } & \text { at the outlet } \\ \text { SS } & \text { Steady State } \\ \mathrm{s} & \text { superficial }\end{array}$

Acronyms and abbreviations

$\begin{array}{ll}\text { BHE } & \text { Borehole Heat Exchanger } \\ \text { CHTM } & \text { Constant heating temperature method } \\ \text { CLS } & \text { Cylinder Line Source } \\ \text { CPT } & \text { Cone Penetration Test } \\ \text { DTRT } & \text { Distributed thermal response test } \\ \text { eTRT } & \text { Enhanced thermal response test } \\ \text { erf, erfc } & \text { error function and complementary error function } \\ \text { GCHP } & \text { Ground Coupled Heat Pump } \\ \text { GHE } & \text { Ground Heat Exchanger } \\ \text { GSHP } & \text { Ground Source Heat Pump } \\ \text { HC-TRT } & \text { Heating Cable Thermal Response Test } \\ \text { ILS } & \text { Infinite Line Source } \\ \text { NTU } & \text { Number of Transfer Units } \\ \text { PID } & \text { Proportional-Integral-Derivative } \\ \text { TRT } & \text { Thermal Response Test } \\ \text { TRTWD } & \text { Thermal Response Test While Drilling }\end{array}$

\section{References}

1. Van Wijk, W. R. ed. (1963). Physics of plant environment, North Holland, Amsterdam, Netherlands.

2. C. Zhang, Z. Guo, Y. Liu, X. Cong, D. Peng, A review on thermal response test of ground-coupled heat pump systems, Renewable and Sustainable Energy Reviews, 40 (2014): 851-867.

3. J. D. Spitler, S. E.A. Gehlin, Thermal response testing for ground source heat pump systems - An historical review, Renewable and Sustainable Energy Reviews, 50 (2015): 1125-1137.

4. J. Poppei, R. Schwarz, H. Peron, C. Silvani, G. Steinmann, L. Laloui, R. Wagner, T. Lochbühler, E. Rohner, Innovative improvements of thermal response tests, Swiss Federal Office of Energy, Final Report, 2008.

5. J. Acuña, P. Mogensen, B. Palm, Distributed thermal response test on a U-pipe borehole heat exchanger, Proceedings of Effstock, Stockholm, Sweden, Paper 18, 2009.

6. H. Fujii, H. Okubo, K. Nishi, R. Itoi, K. Ohyama, K. Shibata, An improved thermal response test for U-tube ground heat exchanger based on optical fiber thermometers, Geothermics 38 (2009): 399-406.

7. G. Tuomas, A.M. Gustafsson, Evaluation of ground thermal conductivity from drilling data, International Journal of Rock Mechanics and Mining Sciences 41 (2004): 241-247.

8. H. Wang, C. Qi, H. Du, J. Gu, Improved method and case study of thermal response test for borehole heat exchangers of ground source heat pump system, Renewable Energy 35 (2010): 727-733.

9. J. Raymond, G. Robert, R. Therrien, L. Gosselin, A novel thermal response test using heating cables, Proceedings of World Geothermal Congress 2010, Bali, Indonesia, April 25-29, 2010.

10. A. Zarrella, G. Emmi, R. Zecchin, M. De Carli, An appropriate use of the thermal response test for the design of energy foundation piles with U-tube circuits, Energy and Buildings 134 (2017): 259-270. 
11. P. Pasquier, Interpretation of the first hours of a thermal response test using the time derivative of the temperature, Applied Energy 213 (2018): 56-65.

12. S. Signorelli, S. Bassetti, D. Pahud, T. Kohl, Numerical evaluation of thermal response tests, Geothermics 36 (2007): 141-166.

13. H. Zeng, N. Diao, Z. Fang, A finite line-source model for boreholes in geothermal heat exchangers, Heat Transfer Asian Research 31 (2002): 558-567.

14. L. Lamarche, B. Beauchamp, A new contribution to the finite-line source model for geothermal boreholes, Energy and Buildings 39 (2007): 188-198.

15. T. V. Bandos, Á. Montero, E. Fernández, J. L. G. Santander, J, M, Isidro, J. Pérez, P. J. Fernández de Córdoba, J. F. Urchueguía, Finite line-source model for borehole heat exchangers: effect of vertical temperature variations, Geothermics 38 (2009): 263-270.

16. D. Marcotte, P. Pasquier, On the estimation of thermal resistance in borehole thermal conductivity test, Renewable Energy 33 (2008) 2407-2415.

17. G.A. Akrouch, J.L. Briaud, M. Sanchez, R. Yilmaz, Thermal Cone Test to Determine Soil Thermal Properties, Journal of Geotechnical and Geoenvironmental 142, (2016): 04015085

18. B. Sanner, E. Mands, M.K. Sauer, E. Grundmann, Thermal response test, a routine method to determine thermal ground properties for GSHP design, 9th IEA Heat Pump Conference, Zurich, Switzerland, May 20-22, 2008.

19. P. Mogensen, Fluid to Duct Wall Heat Transfer in Duct System Heat Storages. Proc. Int. Conf. Subs Heat Storage, 652-657, 1983.

20. C. Eklöf, S. Gehlin, A mobile equipment for thermal response test, Master of Science Thesis: Luleå University of Technology, Sweden, 1996.

21. W.A. Austin, Development of an in situ system for measuring ground thermal properties, Master of Science Thesis, Oklahoma State University, USA, 1998.

22. S. Gehlin, B. Nordell, Determining undisturbed ground temperature for thermal response test, $A S H R A E$ Transactions 109 (2003).

23. H.J.L. Witte, G.J. van Gelder, J.D. Spitler, In situ measurement of thermal conductivity: the Dutch perspective, ASHRAE Transactions 108 (2002).

24. P. Eskilson, J. Claesson, Simulation Model for thermally interacting borehole, Numerical Heat Transfer 13 (1988): 149-165.

25. H.S. Carslaw, J.C. Jaeger, Heat conduction in solids, Clarendon Press, Oxford, 1959.

26. A Franco, An apparatus for the routine measurement of thermal conductivity of materials for building application based on a transient hot-wire method, Applied Thermal Engineering 27 (2007), 2495-2504

27. A.M. Gustafsson, B. Nordell, Thermal response test while drilling, Ecostock 2006, 10th International conference on thermal energy storage, The Richard Stockton College of New Jersey, USA, 2006.

28. J. Poppei, R. Schwarz, H. Peron, N. Mattsson, L. Laloui, R. Wagner, E. Rohner, Innovative improvements of thermal response tests, Project commissioned by Swiss Federal Office of Energy, Intermediate Report, 2006.

29. ASHRAE. Geothermal energy. In: ASHRAE Handbook Heating, Ventilating, and Air-Conditioning Applications. American Society of Heating, Refrigerating and Air-Conditioning Engineers, Atlanta, USA, pp. 32.1-32.30, 2007.

30. M.A. Bernier, Closed-loop ground-coupled heat pump systems, ASHRAE Journal, 2006.

31. Ministerial Decree 14 January 2008: Technical Norms for Constructions, 2008, (in Italian).

32. CEN: Eurocode 8: Design of structures for earthquake resistance, Part 3: Assessment and retrofitting of buildings. June 2004, Doc. CEN/TC250/SC8/N388B. Comité Européen de Normalisation, Bruxelles (2004).

33. J.M. Duncan, S.G. Wright, T.L. Brandon, Soil strength and Slope Stability, J. Wiley, 2014

34. F. Kreith, R. M Manglik, M.S Bohn, Principle of Heat Transfer, 7 ed., Cengage Learning, 2012. 